\title{
CLOSED QUOTIENT AND SPECTRAL MEASURES OF FEMALE ADOLESCENT SINGERS IN DIFFERENT SINGING STYLES
}

Christopher Barlow $^{1}$ (corresponding author) and Jeannette LoVetri ${ }^{2}$

${ }^{1}$ School of Computing and Communications, Southampton Solent University, UK

Email: christopher.barlow@solent.ac.uk

Tel: +44 (0) 2380319213

Fax: +44 (0) 2380339441

${ }^{2}$ The Voice Workshop ${ }^{\circledR}$, Manhattan, NY, USA

This research project is supported by the Arts and Humanities Research Council of the UK: Grant number AH/E000721X/1.

Word count 2366

Abstract word count: 246

Figures: 4

Tables: 1 


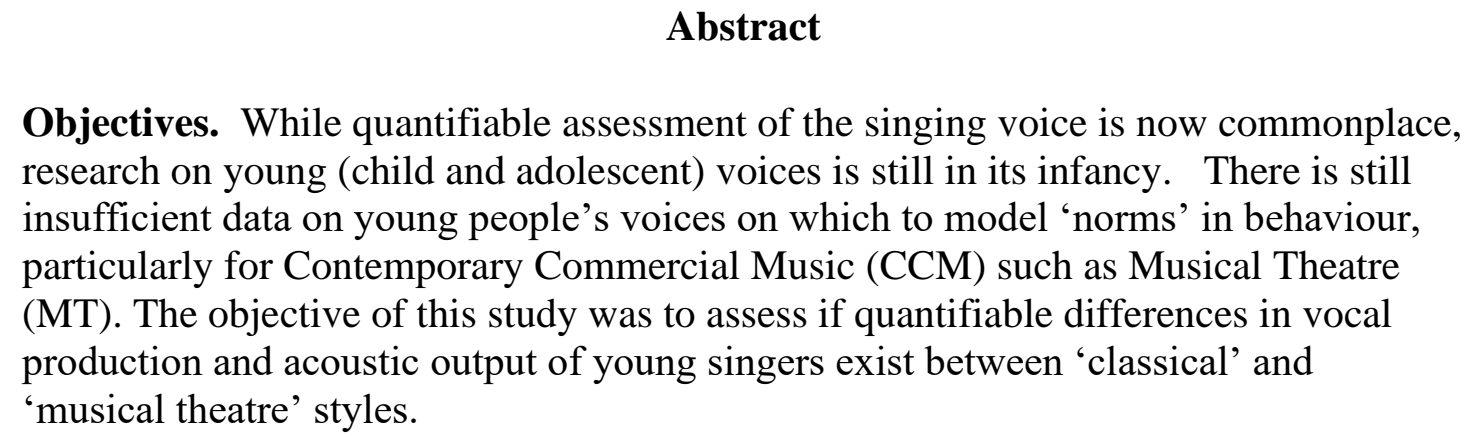

Abstract

Objectives. While quantifiable assessment of the singing voice is now commonplace, research on young (child and adolescent) voices is still in its infancy. There is still insufficient data on young people's voices on which to model 'norms' in behaviour, particularly for Contemporary Commercial Music (CCM) such as Musical Theatre (MT). The objective of this study was to assess if quantifiable differences in vocal production and acoustic output of young singers exist between 'classical' and 'musical theatre' styles.

10 Study Design. The study was a prospective cohort study of 20 adolescent female 11 singers aged 12-17 training their voices using a system which includes both 'classical' 12 and 'musical theatre' styles.

13 Methods, The study examined Laryngographically derived Closed Quotient (CQ), 14 Average Vowel Spectra (AVS) and Long Term Average Spectra (LTAS) measures of 15 the sung voices of voices of singers in 'classical' and 'musical theatre' styles. 16 Results The spectral slope was shallower for the MT voice and Mean CQ was 17 significantly higher across the pitch range when singing in a MT style than in a 18 'classical'. The second to fifth harmonics were stronger in the MT style than in 19 classical, with a significant difference between the two styles.

20 Conclusion. The increase in intensity in the first five harmonics was 21 disproportionately higher than the increase in CQ. Results therefore suggested that 22 MT singing primarily uses change in resonance strategy rather than raised vocal tension to achieve the tonal changes associated with the genre.

Keywords: Singer; Adolescent; Musical Theatre; Closed Quotient; LTAS; AVS 26 


\section{Abstract}

Objectives. While quantifiable assessment of the singing voice is now commonplace, research on young (child and adolescent) voices is still in its infancy. There is still insufficient data on young people's voices on which to model 'norms' in behaviour, particularly for Contemporary Commercial Music (CCM) such as Musical Theatre (MT). The objective of this study was to assess if quantifiable differences in vocal production and acoustic output of young singers exist between 'classical' and 'musical theatre' styles.

Study Design. The study was a prospective cohort study of 20 adolescent female singers aged 12-17 training their voices using a system which includes both 'classical' and 'musical theatre' styles.

Methods, The study examined Laryngographically derived Closed Quotient (CQ), Average Vowel Spectra (AVS) and Long Term Average Spectra (LTAS) measures of the sung voices of voices of singers in 'classical' and 'musical theatre' styles. Results The spectral slope was shallower for the MT voice and Mean CQ was significantly higher across the pitch range when singing in a MT style than in a 'classical'. The second to fifth harmonics were stronger in the MT style than in classical, with a significant difference between the two styles.

Conclusion. The increase in intensity in the first five harmonics was disproportionately higher than the increase in CQ. Results therefore suggested that MT singing primarily uses change in resonance strategy rather than raised vocal tension to achieve the tonal changes associated with the genre.

Keywords: Singer; Adolescent; Musical Theatre; Closed Quotient; LTAS; AVS

\section{Introduction}

The quantification of the singing voice has been of increasing interest to the voice science community for a number of years now, and the use of techniques such as Electroglottography/Laryngography (EGG), (e.g. Howard et al [1], Howard [2]), Inverse Filtering (e.g. Rothenberg, [3]) Long Term Average Spectra (LTAS) (e.g. Mitchell and Kenny [4]) have been widely used to assess vocal production in adult singers, primarily from the western classical tradition.

Outside this particular demographic group, the data on singers' voices is still limited, with only relatively a small amount published on Contemporary Commercial Music (CCM) [5] such as Musical Theatre (MT), Pop, Folk, Rock, Gospel and many other genres. While there are studies in these areas, particularly on Musical Theatre (e.g. Evans and Howard [6] and Bjorkner et al. [7]), as yet these are few in number.

The study of young, particularly adolescent voices has also been distinctly limited. A number of studies have examined quantifiable aspects of young singers' voices from a variety of perspectives. These have included using Laryngographically derived vocal fold Closed Quotient (CQ), (e.g Pedersen [8], Barlow and Howard [9]), inverse filter derived CQ (Mecke and Sundberg, [10]), and voice range profile (VRP) (McAllister et al, [11]). However, despite this, quantifiable voice analysis of young singers to inform use of biofeedback tools is still limited in scope and quantity. There is an overall lack of a comprehensive corpora of data [12] which can be used to assess 'norms' of young voices.

Of the available data, the majority of studies have focused on the young 'classical' 
1 (bel canto) chorister - particularly the male voice (e.g. [13]), with a smaller number of 2 studies focusing on female choristers e.g. [14], [15]. There is a particular lack of 3 research on young voice production for Contemporary Commercial Music (CCM), 4 despite the fact that young people are still the most likely demographic group to organisation Stagecoach ® alone has over 39,000 students training in acting, dancing and singing, [17], yet there is currently very little published research on the voices of young theatre singers.

This study examines measurable parameters of twenty female students from the Brooklyn Youth Chorus Academy (C) (BYCA) ${ }^{1}$ who train for both classical and musical theatre styles of singing. The study aims to ascertain if quantifiable differences occur in voice production by the same student singing in both classical and musical theatre styles, and also aims to develop the beginnings of a model of the voices of young theatre singers.

\section{Methods}

20 BYCA subjects aged between 12 and 17 years were recorded speaking and singing. Recordings were made using a Laryngograph $₫$ headset mounted electret reference microphone to record the speech signal (Sp), at a distance of $\sim 9 \mathrm{~cm}$ from the mouth, and a Laryngograph ${ }^{\circledR}$ which was used to record the Laryngographic signal (Lx). The Lx signal was viewed on an oscilloscope during the recording in order to ensure that an adequate amplitude of the Lx signal was maintained. If the signal dropped to a low level the electrodes were repositioned and the protocol repeated. Recordings were made using the Digital Laryngograph ${ }^{\circledR}$ directly onto a Toshiba Libretto micro-laptop with $1 \mathrm{~Gb}$ RAM and a Pentium Mobile processor running at 1.2GHz. Sampling rate was $22.05 \mathrm{kHz}$ and bit resolution was 16 bit. Approval of the research was given by the Ethics Committee of Southampton Solent University and both subject and parental/guardian permission was given.

Subjects were recorded singing a verse of 'happy birthday' in a 'classical' (chorister) style in the key of $\mathrm{C}$ Major and then repeating it in a 'Musical Theatre' style. The verse was sung between $\mathrm{C} 4(\sim 261 \mathrm{~Hz})$ and $\mathrm{C} 5(\sim 522 \mathrm{~Hz})$.

Students were given a key note and a tempo ( 90 BPM) before singing the piece unaccompanied. In order to control loudness variation subjects were asked to sing the song mezzo-forte in both vocal styles. If considered too loud or too quiet, the singer was asked to repeat the verse.

Using a 'universally' known piece ensured that all subjects were familiar with the song. Audio files were normalised for analysis and SpectraLab (C) was used to generate Long Term Average Spectra (LTAS) of the entire verse for all 20 students

\footnotetext{
${ }^{1}$ The Brooklyn Youth Chorus Academy $\odot$ is a uniquely positioned organisation, working with a large number of international names from both the CCM and Classical music worlds. The chorus regularly performs alongside artists as disparate as Elton John and the New York Philharmonic Orchestra. As such the singers need to be able to adapt their vocal style according to the musical genre being performed.

Cross-Choral Training ${ }^{\circledR},(\mathrm{C}-\mathrm{CT})$ is BYCA's program for developing vocal and musicianship skills in a choral setting. C-CT enables the singers to intentionally perform in a variety of coordinated adjustments and vowel sound qualities so the chorus can easily respond to the musical and expressive demands of diverse repertoire including both CCM and 'classical' styles of performance and can sing any style of music appropriately.
} 
using a $3^{\text {rd }}$ octave filter bandwidth, Hanning window with $75 \%$ overlap and an FFT size of 2048 samples. A mean spectrum for each style was plotted across the group. Recordings of the 10 most experienced students, with between 4 years and 9 years training under the C-CT $®$ system, all aged between 14 and 17 years were analysed in more detail. 5 notes from the song at $3^{\text {rd }}$ octave intervals (root, $3^{\text {rd }}, 5^{\text {th }}, 7^{\text {th }}$ and octave) were extracted for detailed laryngographic and acoustic analysis. Notes were chosen across the range to analyse relationships between pitch and production. These notes were chosen to be at $3^{\text {rd }}$ octave intervals as this frequency resolution is commonly used for spectral analysis. This interval would also allow effective separation of the fundamental frequencies for the purpose of analysis allowing a more detailed comparison of the different styles than available using the LTAS of the entire song.

Average Vowel Spectra (AVS) were also derived from a $500 \mathrm{~ms}$ steady-state portion of each of the specified notes, to give a direct comparison between styles of notes across the pitch range of the song. The AVS used a narrowband filter with FFT size of 4096 samples, Hanning window and overlap of $75 \%$.

The relative amplitude of harmonic partials up to the 6th (referenced to the fundamental) for each note was calculated from this data. Mean CQ was also calculated for each note from which AVS was extracted, using the same sample in order to give a direct comparison of vocal function and resultant acoustic output.

From the notes selected for analysis, two notes were on the vowel $\mathfrak{x}$ ('happy'), one on the vowel $\mathbf{3}^{\mathbf{r}}$ ('birth') and two on the vowel $\mathbf{u}$ ('to' and 'you'). The musical phrase is shown in Figure 1.

Figure 1: 'Happy birthday' - syllables selected for analysis circled.

\section{Results}

The mean LTAS curves are shown in Figure 2. While mean spectral slope is very similar between the styles over the lowest notes, from around $350 \mathrm{~Hz}$ spectral slope for the 'classical' voice is considerably steeper than for the 'theatre' voice, with a mean intensity $3 \mathrm{~dB}$ higher than the 'classical' voice across the range, with a maximum difference of around $6 \mathrm{~dB}$ (double the intensity) ad a range of variation up to $30 \mathrm{~dB}$. A one tailed, paired students t-test in XLStat ${ }^{\circledR}$ demonstrates a significant difference between the mean LTAS of the two vocal styles $(\mathrm{p}=0.00029)$.

Figure 2: $3^{\text {rd }}$ octave Normalised LTAS curves for 'classical' and 'theatre' voices From the analysis of AVS the 'theatre' voice demonstrated higher relative amplitudes than 'classical' across all harmonics up to the sixth (Table 1), and particularly in the first three harmonics. For many notes sung in 'theatre' the first 3 harmonics are stronger than the fundamental and the spectral slope is relatively shallow over the first 5 harmonics, with a mean slope of $\sim 6 \mathrm{db} /$ octave, compared to $\sim 11 \mathrm{~dB} /$ octave for the 'classical' voice A one tailed paired student's T-test of the means demonstrated a significant difference between the two data sets $(\mathrm{p}=0.010)$. The 'classical' voice shows much weaker harmonics particularly above the third harmonics, and a much steeper spectral slope.

Table 2: Mean CQ\% and Relative AVS for specified pitches/vowels in each style

Mean Closed Quotient for each note in each style was derived and results are shown in figure 3. Mean CQ for 4 of the 5 notes analysed is higher for the 'theatre' voice 
than the classical, with the mean for C5 being nearly identical. Analysed as individual singers across all notes, 76\% of mean CQs were higher in 'theatre' voice than in 'classical'. A one tailed paired student's T-test of the means demonstrated a significant difference between the two data sets $(\mathrm{p}=0.018)$.

Figure 3: Mean CQ\% and standard deviation for selected pitches in each style

There is a relationship between mean CQ and sung pitch for each style. For the 'classical' voice mean CQ starts at $26.2 \%$ and decreases slightly with increased pitch up to G4 (24.6\%), and then rises with pitch to B4 and C5 (28.3\%). Mean CQ of the 'theatre' voice is higher at C4 (31.1\%), but otherwise shows a similar pattern, again decreasing slightly with increased pitches to G4 (29.2\%), and rising to B4 (33.6\%), though CQ drops slightly again at C5 to $31.1 \%$.

\section{Discussion}

Previous studies by the authors on classically trained choristers in the UK [18], demonstrated a relationship between CQ and pitch for this style of singing. The pattern of mean CQ against pitch for the classical voice is almost exactly replicated in this sample group, in which Closed Quotient falls with increasing pitch up to G4 and rises above G4. This suggests a register transition around G4, which is supported by the findings of Wurgler [19] who identified this point as a register transition for young voices. These results suggest that the 'classical' singing style used by the BYCA is the same as that used by other conventionally 'classical' youth choirs. The 'theatre' style appears to have much the same relationship between CQ and pitch as the 'classical', with a decrease in CQ up to G4 and then a slight increase again. The key difference is that the 'theatre' voice uses higher mean closed quotient values for most pitches.

The results clearly show consistent differentiation in both vocal function and acoustic output between the two different singing styles. The Average Vowel Spectra show stronger harmonics relative to the fundamental for the 'theatre' voice compared to the 'classical' style of singing.

The variations in amplitude across the spectrum indicate potential differences in both voice source and resonance strategies for the performer between the two different singing styles. Nordstrom and Sundberg [20] indicate that spectral tilt can be caused by variation in vocal loudness. As each subject in this study performed mezzo-forte in both styles, loudness variation was minimised. The degree of effect of vocal loudness on spectral tilt also decreases with increased volume, particularly for young voices [10], so that this effect will have been minimized for the subjects in the study.

Scherer [21] suggested that increased vocal tension increases the strength of harmonics and decreases the spectral slope of the glottal waveform. Evans and Howard [6] demonstrated that Adult 'Belt' voices use significantly more vocal tension in phonation than classical 'bel canto' voices, which was evidenced by raised CQ values.

The CQ results appears to support this finding, showing a slightly raised CQ for 'theatre' singing compared to 'classical'. This possibly suggests that there would be a flatter spectrum from the glottal waveform. However, although a statistically significant increase in CQ between the two styles is evident, the difference in CQ is relatively small, $(\sim 5 \%)$ and the effect that this would have on vocal production is negligible. 
The existence of a positive slope over the first 3 harmonics suggests use of vocal tract resonances in 'theatre' singing to enhance this part of the spectrum, possibly a form of formant 'tuning'. This is supported by the spectrum of certain of the vowels - for example the vowel $\mathfrak{x}$ sung at $\mathrm{C} 4$ appears has a peak amplitude indicating a first formant at $\sim 800 \mathrm{~Hz}$ for the 'classical' voice (indicated by Kent and Read to be within the expected region for adolescent voice [22]), but a peak amplitude around $1000 \mathrm{~Hz}$ for the theatre voice (figure 4). This higher formant frequency could give the characteristically 'bright' and 'edgy' sound to the voice of the young musical theatre singers compared to the 'rounded' tone of a classically trained singer.

\section{Figure 4: Relative intensity of spectrum relative to fundamental for $æ$ at $\mathrm{C} 4$}

A key point of interest here is that there is a relatively small increase in closed quotient while there is considerably higher amplitude of harmonics 1-6 relative to the fundamental series of the acoustic output. The mean increase in closed quotient between 'classical' and 'theatre' is $4.1 \%$, from $26.6 \%$ to $30.7 \%$, considerably lower than the voices exhibited by adult 'belt' voices $[6,7]$. Overall the closed quotient values for both voice types are generally lower than those displayed by adults analysed in similar studies $[2,6]$. The mean difference in relative amplitude between genres across the first 6 harmonics is $7 \mathrm{~dB}$ (123\% increase).

\section{Conclusions}

Results indicate that there are significant and quantifiable differences in vocal production and acoustic output of young singers between the 'classical' and 'musical theatre' styles of singing.

Results demonstrate an higher vocal fold Closed Quotient, although it is suggested that this increase is of such a small amount that it would make little functional difference to the voice, though it is possible that it may slightly reduce the spectral slope of the glottal waveform.

However, as the increase in relative strength of the first six harmonics is disproportionate to the change in closed quotient, it is suggested that the primary factor in the difference between musical theatre styles of singing and classical for this age group is in the use of a different voice resonance strategy, which is used to enhance any slight changes in the acoustic waveform caused by a slightly increased Closed Quotient. This resonance is used to enhance the harmonics in order to increase projection, change the tone and give the voice the characteristic 'brightness' of musical theatre voice.

The results suggest that use of a combination of acoustic analysis and voice source analysis could be used to give detailed model of the progression of young voices with training within a vocal genre, which could be used to differentiate between the effects of training and musical genre for young singers. Further research will be required in order to develop a comprehensive model of young musical theatre singers which takes into account differences in age, gender and level of training.

\section{Acknowledgments}

The authors would like to acknowledge the support of Dianne Berkun and Gail Stone of the BYCA without whom this research could not take place. The willing help of the participants is also gratefully acknowledged.

This research project is supported by the Arts and Humanities Research Council: Grant number AH/E000721X/1. 


\section{References}

2 1. Howard, D.M., Lindsey, G.A., Allen, B., Towards the quantification of vocal

3 efficiency. J Voice, 1990; 4, 205-212.

4 2. Howard, D.M. Variation of electrolaryngographically derived closed quotient for

5 trained and untrained adult female singers. J Voice, 1995; 9, 163-172.

6 3. Rothenberg, M. Airflow-Based Analysis of Vocal Function in Gauffin J. and

7 Hammerberg, B. (Eds.), Vocal Fold Physiology: Acoustic, Perceptual, and

8 Physiological Aspects of Voice Mechanisms, 1991; Singular Publishing Group, San

9 Diego, 139-148.

10 4. Mitchell $\mathrm{H}$ and Kenny, D. The effects of open throat technique on long term 11 average spectra (LTAS) of female classical voices. Logoped Phoniatr Vocol 2004; 12 29: 99-118.

13 5. LoVetri, J, and Weekly, E. M: "Contemporary Commercial Music: Who's Teaching 14 What in Non-Classical Vocal Music." J Voice. 2003; 17(2): 207-216.

15 6. Evans, $M$ and Howard, D.M., Larynx closed quotient in female belt and opera 16 qualities: a case study. J Voice, 1993; 2, 7-14

17 7. Björkner E, Sundberg J, Cleveland T, \& Stone E. Voice source differences between registers in female musical theatre singers. J Voice 2006; 20(2):187-197.

19 8. Pedersen, M. Biological Development and the Normal Voice in Puberty.

20 Unpublished PhD thesis, 1997; University of Oulu, Finland.

21 9. Barlow, C., Howard, D.M. Voice source changes in Child and Adolescent subjects 22 undergoing singing training. Logoped Phoniatr Vocol, $2002 ; 27$ (2), 66-73.

10. Mecke, A. and Sundberg, J. Voice source characteristics of Boys' and Girls' singing voice. Proceedings, Int Conf on Voice Physiol and Biomech. 2008, Tampere University, Finland.

11. McAllister, A., Sederholm, E. \& Sundberg, J. Perceptual and acoustic analysis of vocal registers in 10 year old children. Logoped Phoniatr Vocol 2000; 25 (2), 63-71.

12. Welch, G. 'Report from the ESF/SCSS Exploratory workshop on: Voice 2002: European Science Foundation: Brussels.

13. Cooksey, J.M., Do adolescent voices 'break' or do they 'transform'? Voice 1993;

32 2, 15-39.

14. Welch, G.F. Developing young professional female singers in UK cathedrals. Proc. 2nd Int Conf on Physiol Acoust Singing. ; 2004, Denver: National Center for Voice and Speech.

36 15. Gackle, M.L. The Adolescent Female Voice: Characteristics of change and stages of development. Choral J 1991; 31, (8): 17-25.

38 16. Barlow, C.A. Electrolaryngographically derived Voice source changes of child

39 and adolescent subjects undergoing singing training Unpublished $\mathrm{PhD}$ thesis, 2003;

40 University of York, UK.

41 17. Cole, G. Stagecoach Theatre Arts Plc-Annual Report and Accounts 2007;

42 London: Stagecoach Plc. 
1 18. Barlow,C and Howard,D.M. Évaluation Électrolaryngographique des effects des 2 cours de chant et du sexe sur la source vocale des chanteurs and chanteuses

3 prépubères Med Arts, 2005; 52, 12-19.

4 19. Wurgler, P. A Perceptual Study of Vocal Registers in the Singing Voices of 5 Children. Unpublished PhD Thesis: 1990, University of Ohio, USA.

6 20. Nordenberg, M., and Sundberg, J. Effect on LTAS of vocal loudness variation. 7 TMH-QPSR, 2003. 45: 1; 93-100.

8 21. Scherer, R.C. Laryngeal Function during Phonation. In: Sataloff, R.T. (ed.)

9 Voice Science; 2005; San Diego: Plural Press, 167-184

10 22. Kent, R.D. and Read, C. The Acoustic Analysis of Speech $2^{\text {nd }}$ Edn. 2002: New 11 York: Singular Press. 